\title{
Continuous subcutaneous insulin infusion with short-acting insulin analogues or human regular insulin: efficacy, safety, quality of life, and cost-effectiveness
}

\author{
Régis Pierre Radermecker \\ André Jacques Scheen* \\ Division of Diabetes, Nutrition and \\ Metabolic Disorders, Department of \\ Medicine, CHU Sart Tilman, \\ University of Liège, Liège, Belgium \\ *Correspondence to: Prof. André \\ Jacques Scheen, Division of \\ Diabetes, Nutrition and Metabolic \\ Disorders, Department of Medicine, \\ CHU Sart Tilman, University of \\ Liège, B-4000 Liège, Belgium. \\ E-mail: andre.scheen@chu.ulg.ac.be
}

Received: 22 January 2003

Revised: 24 September 2003

Accepted: 14 November 2003

\section{Summary}

Portable insulin infusion devices are effective and safe insulin delivery systems for managing diabetes mellitus, especially type 1 diabetes. Rapidly absorbed insulin analogues, such as insulin lispro or insulin aspart, may offer an advantage over regular human insulin for insulin pumps. Several open-label randomised crossover trials demonstrated that continuous subcutaneous insulin infusion (CSII) with insulin lispro provided a better control of postprandial hyperglycaemia and a slightly but significantly lower glycated haemoglobin level, with lower daily insulin requirement and similar or even less hypoglycaemic episodes. A CSII study comparing insulin lispro and insulin aspart demonstrated similar results with the two analogues, and better results than those with regular insulin. Because these analogues have a quicker onset and a shorter duration of action than regular insulin, one might expect an earlier and greater metabolic deterioration in case of CSII interruption, but a more rapid correction of metabolic abnormalities after insulin boluses when reactivating the pump. These expectations were confirmed in randomised protocols comparing the metabolic changes occurring during and after CSII interruption of various durations when the pump infused either insulin lispro or regular insulin. The extra cost resulting from the use of CSII and insulin analogues in diabetes management should be compensated for by better metabolic control and quality of life. In conclusion, CSII delivering fast-acting insulin analogues may be considered as one of the best methods to replace insulin in a physiological manner by mimicking meal and basal insulin requirements, without higher risk of hypoglycaemia or ketoacidosis in well-educated diabetic patients. Copyright @ 2004 John Wiley \& Sons, Ltd.

Keywords CSII; insulin analogue; insulin aspart; insulin lispro; insulin pump; ketoacidosis

\section{Introduction}

Continuous subcutaneous insulin infusion (CSII), often called insulin-pump therapy, was introduced in the 1970s as a way of achieving and maintaining strict control of blood glucose concentrations in people with type 1 diabetes [1]. Administration by CSII has provided additional flexibility in meal timing and modifying basal insulin replacement in response to circadian rhythms [2]. In the Diabetes Control and Complications Trial (DCCT), although this trial was not specifically designed to compare CSII and multiple daily injection therapies, lower glycated haemoglobin $\left(\mathrm{HbA}_{1 c}\right)$ levels could be achieved with 
CSII because of a greater reproducibility and flexibility of insulin administration [3]. The superiority of CSII on multiple daily insulin injections, that is, better glycaemic control and stability with lower daily doses of insulin and reduction of hypoglycaemic episodes, has been confirmed in several studies $[4,5]$ and in a recent metaanalysis of 12 randomized controlled trials comparing the two treatment modalities [6]. These advantages of CSII, as well as improvements in pump technology and new reimbursement modalities, have led to increasing acceptance and use of insulin-pump therapy [7-11].

Fast-acting insulin analogues offer the advantages of a faster and shorter hypoglycaemic action [12-14]. Numerous studies demonstrated that both insulin lispro [15-18] and insulin aspart [19-23] are able to better control postprandial hyperglycaemia, even when they are injected just before meals. Another advantage is a significant reduction in the risk of hypoglycaemic episodes and severe hypoglycaemia [16,24], as well as nocturnal hypoglycaemia [25], a favourable effect that has been confirmed in a meta-analysis of eight studies [26]. However, the positive impact on average blood glucose control, as assessed by $\mathrm{HbA}_{1 \mathrm{c}}$, was less obvious and could only be demonstrated in clinical trials in which adjustment of basal insulin supplements [27] and/or reduction of snacks [28] were recommended. The interpretation of such results was that while early postprandial hyperglycaemia was reduced by fast-acting insulin analogue, late plasma glucose levels were higher because of the extremely short action of the insulin analogue and the imperfect basal supplementation using intermediate-acting insulin such as NPH insulin once daily [29]. Delayed hyperglycaemia could theoretically be avoided when using the portable pump, as CSII allows adequate insulin delivery throughout the day and night, using variable insulin delivery rates when necessary. In addition, because the concept of CSII is predicated on an immediacy of insulin action [30,31], a rapid-insulin analogue should be ideal. One study demonstrated that potency and purity of insulin lispro were practically unchanged after 2 days of pumping in two different insulin infusion systems when syringes and catheters are replaced at 48-h intervals [32]. Thus, fast-acting insulin analogues are considered as the gold standard insulin for pump therapy, allowing better postprandial and overall glucose control without increasing the risk of hypoglycaemia $[33,34]$. However, in the most recent meta-analysis of the metabolic and psychosocial impact of CSII therapy in adults, adolescents, and children, including a total of 52 studies, consisting of 1547 patients, no single consideration was mentioned about the possible influence of the type of insulin delivered by the pump, short-acting insulin analogue versus regular human insulin, on the various outcomes considered [11].

One of the problems associated with portable pump therapy may be a higher risk of ketoacidotic episodes [35-37]. Indeed, technical problems (pump failure, catheter occlusion or disconnection, skin infection) may impair insulin delivery or insulin absorption and cause acute metabolic disorders. Properties of insulin analogues, that is, soluble, rapid-acting, and uniform absorption, should reduce the size of the subcutaneous insulin depot and, therefore, reduce the time interval between stopping of insulin delivery and occurrence of acute insulin deficiency, on the one hand, and reduce the time interval between administering recovery insulin boluses and reaching plasma-free insulin peaks, on the other hand. Thus, because of the peculiar pharmacokinetic profile of these two short-acting insulin analogues $[15,18,22,23]$, an earlier insulin deprivation might occur in case of CSII interruption, while a more rapid metabolic correction of hyperglycaemia and ketosis might be attained after administration of insulin lispro or aspart than after that of human regular insulin.

This concise review aims at comparing both the efficacy on metabolic control, assessed by $\mathrm{HbA}_{1 \mathrm{c}}$ levels, and safety, assessed by hypoglycaemia and ketoacidosis incidence, in CSII-treated type 1 diabetic patients using either short-acting insulin analogues (lispro or aspart) or human regular insulin. Moreover, we will compare the consequences of CSII interruption in diabetic patients treated either with regular insulin or with insulin lispro, as well as the efficacy of a rescue insulin replacement scheme after restarting the pump following several hours of insulin delivery interruption. Safety concern will also be discussed, especially when using CSII and insulin analogues during pregnancy. Finally, possible advantages on quality of life and cost-effectiveness analysis of these modalities of insulin replacement therapy will be briefly presented.

\section{CSII and metabolic control: insulin lispro versus human regular insulin}

At least six controlled trials compared the efficacy and safety of insulin lispro versus human regular insulin in CSII-treated type I diabetic patients [38-45]. The first pilot, double blind, crossover, comparative study treated 30 diabetic patients for 3 months with insulin lispro and for 3 months with human regular insulin in a randomized order [38]. All boluses were given immediately before the three main meals. At the end of the three-month treatment period, $\mathrm{HbA}_{1 \mathrm{c}}$ levels were significantly lower with insulin lispro compared to those with human regular insulin $(7.66 \pm 0.13$ vs $8.0 \pm 0.16 \% ; p<0.005)$. Onehour postprandial blood glucose concentrations were significantly improved after breakfast, lunch, and dinner with insulin lispro, compared to those with regular insulin. The incidence of hypoglycaemia tended to be lower (NS) with insulin lispro than with regular insulin. The authors concluded that insulin lispro improves glycaemic control in CSII without increasing the risk of hypoglycaemia.

Five open-label, randomized, crossover trials compared insulin lispro with human regular insulin (two successive experimental periods of 2 to 4 months) in type 1 diabetic patients treated with a portable pump [39-43]. In all 
these open studies, except one [43], and in contrast to the previous double-blind trial [38], insulin boluses were given 0 to $5 \mathrm{~min}$ before meals for insulin lispro and 20 to $30 \mathrm{~min}$ before meals for regular insulin. Nevertheless, all trials reported reduced postprandial hyperglycaemia and lower $\mathrm{HbA}_{1 \mathrm{c}}$ levels with insulin lispro as compared to those with regular insulin (Table 1). However, the differences were rather small (from -0.10 to $0.53 \%$ for $\mathrm{HbA}_{1 \mathrm{c}}$ ), although statistically significant, except in the study with the lower number of subjects [39]. The differences in the changes in $\mathrm{HbA}_{1 \mathrm{c}}$ across the studies may be related to duration of study, intensity of glucose control, or timing of insulin bolus doses relative to meals. Hypoglycaemic episodes (usually defined as blood glucose levels $<3 \mathrm{mmol} / \mathrm{L}$ ) were not significantly different between the two treatment modalities in every study (Table 1).

A study demonstrated a positive impact on clinical status and quality of life of switching from regular human insulin to insulin lispro among patients using insulin pumps [44]. These results were confirmed in a long-term study comparing the therapeutic efficacy of insulin lispro with that of buffered regular human insulin in 62 patients on insulin-pump therapy [45]. The patients, initially treated with regular human insulin for 20 months, switched to using insulin lispro for another mean of 20 months. $\mathrm{HbA}_{1 \mathrm{c}}$ level was significantly lower with insulin lispro than with regular insulin $(7.4 \mathrm{vs}$ $7.9 \% ; p<0.001)$. Basal insulin requirements were higher, while pre-meal insulin boluses were lower with insulin lispro than those with regular insulin, the total daily units of insulin being slightly but significantly lower during therapy with the fast-acting insulin analogue. The numbers of mild/moderate and severe hypoglycaemic episodes were similar in the two treatment periods. This first long-term study demonstrates the sustained efficacy of insulin lispro as compared to that of buffered regular insulin in decreasing $\mathrm{HbA}_{1 \mathrm{c}}$, without increasing the incidence of hypoglycaemia, among insulin-pump users.

One case report compared glucose profiles, $\mathrm{HbA}_{1 \mathrm{c}}$ levels, and the risk of severe hypoglycaemia in one patient who successively moved from CSII using regular acting insulin to CSII using insulin lispro, and finally implantable pump with intraperitoneal insulin delivery [46]. Longitudinal data in this patient suggested that insulin lispro only tended to reduce average glycaemia and glycaemic fluctuations as compared to regular insulin, whereas a much greater improvement could be achieved with the implantable pump delivering insulin intraperitoneally, a finding recently confirmed in a pilot controlled study. [47].

Thus, one key advantage of insulin lispro in CSII is the similar or even reduced incidence of hypoglycaemic episodes despite a better overall metabolic control, as compared to that of regular human insulin [33]. One specific experimental trial demonstrated that the counterregulatory hormone responses are maintained with the use of insulin lispro in CSII, compared to that of regular human insulin, resulting in improved hepatic glucose output in response to glucagon [48].

\section{CSII and metabolic control: aspart insulin versus human regular insulin}

It has been demonstrated that both insulin aspart and insulin lispro are indistinguishable from each other with respect to plasma glucose, free fatty acid, and ketone body levels and that they are equally effective in correcting abnormalities in carbohydrate and fat metabolism in patients with type 1 diabetes [49]. Contrasting with the numerous studies, essentially with a randomized crossover design, comparing insulin lispro and regular human insulin in CSII-treated diabetic patients (Table 1), only two studies, both using a parallel-group experimental protocol, compared insulin aspart with regular insulin $[34,50]$.

One randomized open-label study compared the efficacy and safety of insulin aspart $(n=19)$ and buffered regular human insulin $(n=10)$ for 7 weeks [50]. Bolus doses of insulin aspart were administered immediately before meals and those of regular insulin $30 \mathrm{~min}$ before meals. The two insulins were both effective in controlling average daily blood glucose levels and maintaining $\mathrm{HbA}_{1 \mathrm{c}}$ levels $(6.9 \%$ with insulin aspart vs $7.1 \%$ with regular

Table 1. Changes in postprandial hyperglycaemia, $\mathrm{HbA}_{1 \mathrm{c}}$ levels, and incidence of hypoglycaemic episodes in clinical trials comparing insulin lispro with human regular insulin in type 1 diabetic patients treated with continuous subcutaneous insulin infusion

\begin{tabular}{|c|c|c|c|c|c|c|c|c|c|}
\hline \multirow[b]{2}{*}{$\begin{array}{l}\text { References } \\
\text { Zinman et al. } 1997 \text { [38] } \\
\text { Schmauss et al. 1998 [39] } \\
\text { Melki et al. 1999 [40] } \\
\text { Renner et al. 1999 [41] } \\
\text { Johansson et al. 2000 [42] } \\
\text { Raskin et al. } 2001 \text { [43] } \\
\text { Garg et al. 2000 [45] } \\
\text { Bode et al. } 2002 \text { [34] }\end{array}$} & \multirow[b]{2}{*}{$\begin{array}{l}n \\
30 \\
11 \\
39 \\
113 \\
41 \\
58 \\
62 \\
28(*)\end{array}$} & \multirow{2}{*}{$\begin{array}{c}\begin{array}{c}\text { Period } \\
\text { (months) }\end{array} \\
2 \times 3 \\
2 \times 3 \\
2 \times 3 \\
2 \times 4 \\
2 \times 2 \\
2 \times 3 \\
2 \times 20 \\
4\end{array}$} & \multirow[b]{2}{*}{$\begin{array}{c}\text { Design } \\
\text { DB CO } \\
\text { Open CO } \\
\text { Open CO } \\
\text { Open CO } \\
\text { Open CO } \\
\text { Open CO } \\
\text { Switch } \\
\text { Open parallel }\end{array}$} & \multicolumn{2}{|c|}{$\begin{array}{c}\text { Postprandial } \\
\text { hyperglycaemia } \\
\Delta(\mathrm{mmol} / \mathrm{L})\end{array}$} & \multicolumn{2}{|c|}{$H b A_{1 c} \Delta(\%)$} & \multicolumn{2}{|c|}{$\begin{array}{c}\text { Hypoglycaemia } \Delta \\
\text { (30 days) }\end{array}$} \\
\hline & & & & $\begin{array}{c}-1.44 \\
-1.50 \\
-1.64 \\
-1.60 \\
-1.50 \\
-2.04 \\
\text { NA } \\
0\end{array}$ & $\begin{array}{c}p=0.006 \\
p=0.030 \\
p=0.001 \\
p=0.001 \\
p=0.001 \\
p=0.012 \\
\text { NA } \\
\text { NS }\end{array}$ & $\begin{array}{l}-0.34 \\
-0.35 \\
-0.53 \\
-0.1 \\
-0.2 \\
-0.23 \\
-0.50 \\
+0.03\end{array}$ & $\begin{array}{c}p<0.005 \\
\text { NS } \\
p<0.01 \\
p<0.02 \\
p<0.05 \\
p<0.005 \\
p<0.001 \\
\text { NS }\end{array}$ & $\begin{array}{l}-1.6 \\
+0.8 \\
-0.9 \\
-0.4 \\
+1.7 \\
0 \\
-0.4 \\
-0.4\end{array}$ & $\begin{array}{l}\text { NS } \\
\text { NS } \\
\text { NS } \\
\text { NS } \\
\text { NS } \\
\text { NS } \\
\text { NS } \\
\text { NS }\end{array}$ \\
\hline
\end{tabular}

$\Delta$, Value with insulin lispro minus value with human regular insulin; $\mathrm{CO}$, crossover; DB, double blind; Switch, from regular insulin to insulin lispro; NA, not available; NS, not significant; (*) 59 patients received human regular insulin. 
insulin, NS). A similar number of patients experienced hypoglycaemia (blood glucose $<2.5 \mathrm{mmol} / \mathrm{L}$ ) during the study $(74 \%$ with insulin aspart vs $60 \%$ with regular insulin; NS). The authors concluded that insulin aspart and regular human insulin were effective and well tolerated when used in CSII therapy.

Only one randomized study compared the three types of insulin, that is, insulin aspart $(n=59)$ versus buffered human insulin $(n=59)$ versus insulin lispro $(n=28)$ [34]. In this recent multicentre, open-label, randomized, parallel-group study, bolus insulin doses were administered $30 \mathrm{~min}$ before meals for regular insulin or immediately before meals for the two insulin analogues. After 16 weeks of treatment, mean changes in baseline $\mathrm{HbA}_{1 \mathrm{c}}$ values were not significantly different between the three groups $(0.00 \%$ for aspart, $0.15 \%$ for regular, and $0.18 \%$ for lispro; NS). The rates of hypoglycaemic episodes per patient per month were similar in the three groups. The conclusion was that insulin aspart in CSII was as efficacious and well tolerated as regular insulin and insulin lispro and is a suitable insulin for external pump therapy.

Thus, the use of a short-acting insulin analogue in the pump improves $\mathrm{HbA}_{1 \mathrm{c}}$ and blood glucose stability, without increasing the risk of hypoglycaemia. However, frequent blood glucose self-monitoring is required in order to optimize insulin adjustments [51].

\section{Interruption of CSII with regular insulin: comparison with normal functioning of the pump}

CSII use was initially associated with an overall increased frequency of diabetic ketoacidosis $[35,36]$. However, as pointed out in a recent meta-analysis of 52 studies dealing with insulin-pump therapy [11], this increased risk of diabetic ketoacidosis was not evident in studies published after 1993, suggesting that CSII may no longer be associated with a greater risk of ketoacidotic episodes compared to other forms of insulin administration. It may be that earlier data on the increased risk of diabetic ketoacidosis led clinicians to emphasise ketoacidosis prevention with their patients and manufacturers to improve the security of insulin pumps by inserting several alarms in case of malfunction of the device. Thus, with proper education and pump practice, the frequency of ketoacidosis appears to be the same on CSII and insulin injection therapy [10].

In an original pilot study, our group investigated the changes in blood glucose, plasma non-esterified fatty acids (NEFA), 3-hydroxybutyrate (3-OHB), glucagon, and free insulin in eight $\mathrm{C}$-peptide-negative type 1 diabetic patients whose pumps were deliberately stopped between $23.00 \mathrm{~h}$ to $05.00 \mathrm{~h}$ [52]. A control test with the pump functioning normally was carried out in each patient and the experimental protocols were carried out in a random order. Considering the values at $23.00 \mathrm{~h}$ as reference, interruption of insulin infusion resulted in (1) a rapid decrease in plasma-free insulin levels, significant after $1 \mathrm{~h}$ and reaching a nadir after $6 \mathrm{~h}$; (2) a rise in blood glucose that was significant at hour 3 and reached $17.4 \pm 1.9 \mathrm{mmol} / \mathrm{L}$ at hour 6 ; (3) a moderate increase in plasma NEFA concentrations that remained in the range of 700 to $800 \mu \mathrm{mol} / \mathrm{L}$; (4) an early and linear rise in plasma 3-OHB, significant after $1 \mathrm{~h}$ and averaging $1290 \pm 140 \mu \mathrm{mol} / \mathrm{L}$ after $6 \mathrm{~h}$, with presence of ketonuria; and (5) a late increase (hour 5) in plasma glucagon.

Besides insulin deprivation due to pump arrest, counterregulatory hormones play a significant role in the increase of blood glucose and 3-OHB levels, as such increments were reduced almost by half after either continuous intravenous infusion of somatostatin or a single subcutaneous injection of octreotide (a long-acting somatostatin analogue) inhibiting both growth hormone and glucagon secretion [review in 37]. Our group demonstrated that several other factors significantly influence the amplitude and kinetics of metabolic deterioration: the residual insulin secretion (less deterioration in C-peptide positive diabetic patients), the quality of previous metabolic control (less deterioration in subjects with prevailing normoglycaemia), insulin concentration in the pump cartridge (less deterioration when using concentrated insulin), and the presence of insulin antibodies (less deterioration in patients with high circulating IgG antibodies) [37]. Finally, as expected, the duration of CSII interruption plays a crucial role. We demonstrated that 1-h pump arrest does not significantly alter the metabolic profile in well-controlled diabetic patients, while a 2-h period of CSII interruption is enough to induce a significant rise in plasma glucose and 3-OHB levels; in this condition, additional insulin boluses are required to prevent or correct the metabolic disorders [53].

Thus, the prolonged, either intentional or accidental, interruption of CSII delivering regular human insulin has metabolic consequences that should be carefully borne in mind. These consequences reflect the increased risk of ketoacidotic episodes reported in diabetic patients treated with CSII [37]. This risk can be markedly reduced if regular home blood glucose monitoring is performed and if the well-educated diabetic patient reacts rapidly to incipient metabolic deterioration with the administration of insulin supplements based on a regimen determined by blood glucose and the presence or absence of ketonuria [37,51]. From a practical point of view, in well-controlled diabetic patients, it seems reasonable to permit short-term interruption of CSII for up to $1 \mathrm{~h}$, while longer interruption must be followed by insulin supplements [54].

\section{Interruption of CSII with insulin lispro: comparison with regular insulin}

Three controlled studies compared the metabolic consequences of CSII interruption when using insulin lispro versus regular insulin [55-57]. All trials studied Cpeptide-negative type 1 diabetic patients, and measured 
at regular intervals various metabolic (plasma glucose, NEFA, 3-OHB, ketonuria) and hormonal (plasma-free insulin, glucagon) parameters. However, the protocols differed as far as the study design (parallel vs crossover), the duration of CSII interruption ( 5 vs 6 vs $9 h$ ), the time period of pump arrest (nocturnal vs diurnal), and the delay since the last insulin bolus administration were concerned (Table 2).

A total of 18 well-controlled type 1 diabetic patients were studied: 9 received human regular and 9 received insulin lispro. Basal insulin infusion was stopped from 03.00 to $09.00 \mathrm{~h}$ [55]. Plasma glucose concentrations rose to $13.8 \pm 1.9$ and $16.0 \pm 1.7 \mathrm{mmol} / \mathrm{L}$ in the regular insulin- and insulin lispro-treated groups respectively (NS). No significant differences were seen between the therapy groups at any time in the insulin levels or in the concentrations of plasma glucose or 3-OHB. The authors concluded that interruption of the basal insulin infusion in the middle of the night does not result in more rapid metabolic deterioration in patients treated with lispro compared to those treated with regular insulin. However, this trial used a parallel-group study design rather than a crossover protocol, which may hinder the demonstration of differences between the two insulins as different groups of patients were used for the comparison.

An open-label randomized crossover trial investigated seven type 1 diabetic patients treated with portable pump. CSII was interrupted from 22.00 to $07.00 \mathrm{~h}$ the next day in two experimental conditions: either with regular insulin or with insulin lispro [56]. With insulin lispro, the metabolic changes developed 1.5 to $2 \mathrm{~h}$ earlier than with regular human insulin. After $3 \mathrm{~h}$, blood glucose averaged $4.93 \pm 2.87 \mathrm{mmol} / \mathrm{L}$ with regular insulin and $8.97 \pm 3.48 \mathrm{mmol} / 1$ with insulin lispro $(p<0.05)$. Decreases in base excess were significantly greater with insulin lispro $(-1.69 \pm 0.83 \mathrm{mmol} / \mathrm{L})$ than with regular insulin $(-0.41 \pm 1.04 \mathrm{mmol} / \mathrm{L} ; p<0.05)$.

Another randomized, crossover, open-label trial comparing insulin lispro and regular insulin was performed in 10 type 1 diabetic patients [57]. CSII was interrupted from 07.00 to $12.00 \mathrm{~h}$. The plasma-free insulin level decreased significantly with the two treatments, but was significantly lower with lispro than with regular insulin $(p<0.05-0.01)$. The plasma glucose level was significantly higher in the insulin lispro group than in the regular insulin group from 120 until $300 \mathrm{~min}$ after stopping CSII $(13.93 \pm 3.77$ vs $10.77 \pm 4.38 \mathrm{mmol} / \mathrm{L}$, $p<0.05$ at $180 \mathrm{~min}$ and $17.04 \pm 3.27$ vs $12.98 \pm 4.33$ mmol/L, $p<0.01$ at $300 \mathrm{~min}$ ). Plasma NEFA concentrations increased more rapidly and were significantly higher in the lispro group than in the regular group $(p<0.05-0.01)$. Plasma 3-OHB increased earlier with lispro (60 vs $120 \mathrm{~min}$ ), but was not statistically different between the two treatments.

Thus, the two trials using a randomized crossover study protocol, allowing a direct comparison in the same diabetic patients, reported similar results and concluded that metabolic deterioration occurred earlier and was of greater amplitude with insulin lispro than with human regular insulin [56,57].

\section{Metabolic correction with regular insulin versus insulin lispro replacement scheme}

After a 6-h CSII nocturnal (23.00-05.00 h) interruption using regular insulin, a scheme for a prompt return to adequate control was tested in eight C-peptide-negative type 1 diabetic patients [52]. This scheme consisted of insulin supplements administered via the pump and based on blood glucose monitoring and semi-quantitative evaluation of ketonuria. Resetting the pump at its basal rate at $05.00 \mathrm{~h}$ and giving insulin supplements $(2-8 \mathrm{U}$ ) at $06.45 \mathrm{~h}$ (with the usual breakfast dose) and again at $10.00 \mathrm{~h}$ have proved efficacious in restoring rapidly satisfactory metabolic control. Indeed, plasma glucose and 3-OHB levels were similar at noon, both after the CSII interruption test and in the test with normal functioning of the pump throughout the night. This study allowed establishing precise guidelines that permit the patient to restore adequate metabolic control within a few hours on the basis of simple blood and urine determinations performed by the patient himself/herself [54].

Table 2. Changes in plasma-free insulin, glucose, and 3-OHB levels during CSII interruption in three trials comparing regular insulin with fast-acting insulin lispro. When precise data were not directly available in the original paper, they were estimated from the curves of the corresponding figures

\begin{tabular}{|c|c|c|c|c|c|c|c|}
\hline \multicolumn{2}{|c|}{ References } & \multicolumn{2}{|c|}{$\Delta$ Free insulin (pmo//L) } & \multicolumn{2}{|c|}{$\Delta$ Glucose $(\mathrm{mmol} / \mathrm{L})$} & \multicolumn{2}{|c|}{$\triangle 3-\mathrm{OHB}(\mu \mathrm{mol} / \mathrm{L})$} \\
\hline Attia et al. 1998 [55] & Off/Regular $(n=9)$ & -47 & & +13.0 & & +910 & \\
\hline & & & NS & & NS & & NS \\
\hline (8h-stop of CSIl; parallel) & Off/Lispro $(n=9)$ & -60 & & +12.2 & & +1220 & \\
\hline \multirow[t]{2}{*}{ Reichel et al. 1998 [56]. } & Off/Regular $(n=7)$ & NA & & +10.0 & & $-2.39 \mathrm{BE}(*)$ & \\
\hline & & & NA & & NS & & NS \\
\hline (9h-stop of CSII; crossover) & Off/Lispro $(n=7)$ & NA & & +12.6 & & $-3.27 \mathrm{BE}(*)$ & \\
\hline \multirow[t]{2}{*}{ Guerci et al. 1999 [57] } & Off/Regular $(n=10)$ & -36 & & +4.9 & & +710 & \\
\hline & & & $p<0.05$ & & $p<0.01$ & & $p<0.05$ \\
\hline (5h-stop of CSIl; crossover) & Off/Lispro $(n=10)$ & -43 & & +9.2 & & +1120 & \\
\hline
\end{tabular}

$\Delta$, Value at the end of CSII interruption minus baseline value; (*), base excess (instead of 3-OHB not measured in this study); NA, not available; NS, not significant. 
In the study of Attia et al. [55], patients with plasma glucose levels $>13.9 \mathrm{mmol} / \mathrm{L}$ or moderate ketonuria at the end of a 6-h pump arrest received a single subcutaneous injection of either human regular or insulin lispro. In this insulin-replacement phase, plasma-free insulin levels rose more rapidly in those treated with insulin lispro, reaching a greater peak value $(150 \pm 20$ vs $94 \pm 16 \mathrm{pmol} / 1, p<0.05$, at $60 \mathrm{~min}$ ), while plasma glucose concentrations decreased to a lower nadir after insulin lispro ( $9.7 \pm 0.4$ vs $13.7 \pm 0.7 \mathrm{mmol} / \mathrm{L}, p<0.01$, at $120 \mathrm{~min}$ after insulin administration). Plasma 3-OHB levels decreased rapidly in both groups, the slope of the reduction being more abrupt with insulin lispro, allowing finishing the test with roughly similar values.

In the study performed by Guerci et al. [57], the pump of each patient was reactivated at its usual basal rate at $12.00 \mathrm{~h}$ (after $5 \mathrm{~h}$ of CSSI interruption), at which time the patients ate a similar calibrated lunch and activated their usual pre-lunch insulin boluses. Additionally, a correcting insulin scheme (0-4 U) was given each hour afterwards according to plasma glucose levels and ketonuria. After restarting the pump, the plasma-free insulin peak occurred earlier and was greater with lispro than with regular insulin $(224 \pm 121$ vs $97 \pm 31 \mathrm{pmol} / \mathrm{L} ; p<0.05$ ). As a consequence, plasma glucose concentrations decreased with insulin lispro, but continued to increase with regular insulin during the first $2 \mathrm{~h}$ after restarting the pump (the difference being statistically significant $60 \mathrm{~min}$ after insulin replacement). Plasma NEFA and 3-OHB levels decreased significantly with the two treatments, but more dramatically with lispro treatment.

Thus, the two studies comparing correction schemes with insulin lispro and regular insulin concluded that the fast-acting insulin analogue is more effective in treating mild ketosis and hyperglycaemia following CSII interruption [55,57]. In well-educated patients, this may represent an advantage provided that early detection of the metabolic deterioration is made and prompt adequate response is brought.

\section{Immunoallergic considerations with short-acting insulin analogues during pump therapy}

It has been suggested that CSII [58] as well as long-term intraperitoneal insulin administration via implantable programmable insulin delivery systems [59] may favour the development of insulin antibodies. However, the role of these insulin antibodies on metabolic control remains controversial $[60,61]$. These antibodies might play the role of reservoir in certain circumstances and, for instance, dampen the metabolic deterioration occurring after CSII interruption [62,63]. To our knowledge, no study specifically investigated the development of antibodies during CSII when delivering short-acting insulin analogues.
Insulin lispro and recombinant human insulin have similar immunogenicity [64]. Recently, a multinational, multicentre combination of controlled and non-controlled, open-label studies of 4.5 years' duration evaluated the long-term immunologic profile of subcutaneously administered insulin lispro [65]. By measuring lispro-specific, insulin-specific, and cross-reactive antibodies, it was concluded that the immunogenic profile of patients treated with insulin lispro was comparable to that of patients treated with recombinant human insulin. In addition, the incidence of insulin allergy was not different from that in patients treated with recombinant regular human insulin. Anecdotal reports suggested that both antibody-mediated insulin resistance [66] and generalised allergy to human insulin [67] could be successfully treated with insulin lispro. Insulin desensitization with CSII delivering insulin lispro has been reported in several type 1 diabetic patients [68-70], suggesting that the insulin pump and shortacting insulin may be useful as alternative treatments in insulin allergy.

Lipoatrophy as a cutaneous complication of insulin therapy has been extremely rare since the introduction of recombinant human insulin. Two cases of lipoatrophy associated with lispro insulin have been reported in two insulin-pump-treated diabetic patients [71]. Recently, a singular case in which lipoatrophy occurred in two different locations with both buffered regular human insulin and insulin lispro has been described in a patient treated by CSII [72]. Interestingly, the lispro-induced lipoatrophic area was smaller than that associated with human regular insulin, a difference that might be related to the reduced ability of insulin lispro to aggregate.

\section{CSII with insulin analogues during pregnancy}

CSII has been advocated as an alternative to multipledose insulin injections in diabetic pregnant women as it more closely mimicks physiological insulin delivery and allows better metabolic control [73-75]. Only few studies have investigated the safety of insulin lispro in human pregnancy as far as foetal and maternal outcomes are concerned [76-78]. The risk of severe hypoglycaemic or ketoacidotic episodes may be particularly dramatic in pregnant women, two complications that could be positively or negatively influenced by the use of both CSII and short-acting insulin analogues. Apparently, the metabolic observations made in non-pregnant women were confirmed during pregnancy with a trend to better blood glucose control with lower hypoglycaemic episodes and no significant increase in severe ketoacidotic episodes [73-75]. Because the risk of developing ketoacidosis is higher during pregnancy, the problem of pump arrest should be a matter of concern in pregnant diabetic women. One of the most important criteria in selecting patients for CSII is their willingness to test their capillary glucose levels several times each day [73]. 
This prerequisite is especially important when fast-acting insulin analogue is used in the pump in order to detect early metabolic deterioration and administer insulin bolus to promptly restore adequate metabolic control in welleducated women.

Despite better acceptability, less hypoglycaemia and possibly better glycaemic control, doubts were raised by a few reported cases of congenital anomalies using insulin lispro $[77,78]$. However, some controlled studies were unable to find any increase in the adverse outcome using insulin lispro in diabetic pregnancies, in either gestational or pre-gestational diabetes [77,79]. A recent report on pooled data from seven centres with experience in the use of insulin lispro during pregnancy mentioned comparable outcomes to other large studies using conventional insulin [80]. A recent study examined whether insulin lispro crosses the placenta using the technique of perfusing a human placental lobule in vitro [81]. It showed that insulin lispro is not likely to cross the placenta at a single standard dose and suggested that insulin lispro is unlikely to reach and harm the unborn baby. These results are in agreement with the absence of detectable insulin lispro in the cord blood of newborns from mothers who received continuous intravenous infusion of insulin lispro and dextrose during labour [76].

Only scarce data are available yet on the efficacy and safety of the use of insulin aspart in pregnant women. A recent study demonstrated that effective postprandial glycaemic control in women with gestational diabetes mellitus who required insulin was brought about by insulin aspart, as compared to regular human insulin, through higher insulin peak and lower demand on endogenous insulin secretion [82]. It has been suggested that large prospective randomized clinical trials should be performed for further evaluation of any possible association between the use of insulin lispro or insulin aspart during pregnancy and an increased rate of congenital malformations [79]. Up to now, rapid-acting insulin analogues are not approved for use in pregnancy [83].

In one report, rapid acceleration of proliferative retinopathy was seen during pregnancy in 3 of 10 women with diabetes treated with insulin lispro [84]. In other reports, insulin lispro was not associated with the progression of diabetic retinopathy during pregnancy $[77,85]$. A recent prospective open study of 69 pregnant women with diabetes ( 36 treated with insulin lispro and 33 treated with conventional regular human insulin) confirmed that insulin lispro improves glycaemic control during diabetic pregnancy compared to regular insulin, with no adverse impact on progression of diabetic retinopathy [86].

\section{Education and patient's selection for CSII}

Only well-educated diabetic patients are those who benefit more from CSII. As emphasised by the American Diabetes
Association recommendations [83], CSII therapy should ideally be prescribed, implemented, and followed by a skilled professional team familiar with CSII therapy and capable of supporting the patient. Experience with insulin-pump therapy indicates that candidates for CSII must be strongly motivated to improve glucose control and willing to work with their health-care provider in assuming substantial responsibility for their day-today care. They must also understand and demonstrate appropriate use of the insulin pump and self-monitoring of blood glucose $[10,83]$. Patients who are not compliant on insulin injection regimens will do badly on pump therapy and, in general, should not be selected [10]. All clinical trials demonstrating a significant advantage of short-acting insulin analogues, in comparison with regular human insulin, as far as metabolic control was concerned, were obtained in CSII-treated patients who satisfied all these prerequisites. We can also speculate that only those patients will benefit from an increased quality of life with an acceptable cost-effectiveness ratio when using such sophisticated methods of insulin delivery.

\section{CSII with insulin analogues and quality of life}

Quality of life is an important health outcome, particularly in persons with a chronic disease such as diabetes mellitus. It is therefore important that the ability of patients to comply and their satisfaction with treatment, together with the effect of therapy on overall quality of life, are taken into account by physicians. Both CSII and fast-acting insulin analogues may positively influence the quality of life of diabetic patients.

Among CSII-treated patients, the effectiveness and flexibility of CSII appeared to compensate for problems caused by both the external pump and the subcutaneous catheter, and for the interference with various activities like work, sex, and sport. The favourable disposition towards CSII appears to stem from the feeling that CSII is better than multiple daily injections in achieving good metabolic control and produces a sense of well-being, increased freedom, and greater autonomy [87]. Patient reactions to CSII have been largely enthusiastic and the discontinuation rates low $[10,88]$.

Increased satisfaction with treatment and improved quality of life with insulin lispro relative to regular human insulin have been shown in a number of studies with quality of life as primary and secondary endpoints in diabetic patients [89]. A large majority of patients expressed a preference for insulin lispro over human soluble insulin on the grounds of increased freedom with meal timing and increased independence in everyday activities. However, it should be noted that most of these trials were conducted in an uncontrolled manner. Quality-of-life data were reported in great detail by Kotsanos et al. [90], who based their analysis on a large non-blind randomized comparative crossover trial 
in 1008 patients with type 1 diabetes, of whom 468 were available for quality-of-life assessment. An expanded and modified form of the 'Diabetes Quality of Life Clinical Trial Questionnaire' was used with two diabetes-specific domains (treatment satisfaction and treatment flexibility) being specified as primary outcomes. After 3 months' treatment, only mean treatment flexibility and treatment satisfaction scores were significantly increased relative to baseline to a greater extent with insulin lispro than with human soluble insulin. All other primary and secondary domains of health-related quality-of-life findings were comparable for insulin lispro and regular human insulin. Favourable results were also recently reported in a 6month, multinational, randomized, large, open-label trial comparing insulin aspart with soluble human insulin in 424 adult type 1 diabetic patients on an insulin basal-bolus scheme, but not CSII [91]. Under the study conditions, insulin aspart improved treatment satisfaction and quality of life with regard to diet restriction when compared with human regular insulin, and this effect was judged as being 'not trivial'.

It should be emphasised, however, that none of these studies assessing quality of life included patients treated with CSII and that none of the above-mentioned studies comparing short-acting insulin versus human soluble insulin in CSII-treated patients with type 1 diabetes reported specific data on quality of life.

\section{Pharmacoeconomical aspects of CSII and insulin analogues}

It is inevitable that new treatments for diabetic patients will be considered critically by health-care planners and providers in the prevailing global environment of increasing costs of medical care and pressure for rational allocation of resources [89]. Both portable insulin pumps and short-acting insulin analogues represent an extra cost as compared to classical insulin therapy using conventional insulin injections of human regular insulin. Intensive insulin therapy reduces costs by decreasing complications [92]. However, neither CSII nor shortacting insulin analogues have proven their superiority in reducing the risk of microvascular or macrovascular complications in long-term studies. Thus, the only available data concern the possible reduction of acute metabolic complications, such as severe hypoglycaemic episodes.

A Markov model was recently constructed to estimate the costs and outcomes for patients with type 1 diabetes treated with CSII compared to those treated with multiple daily injections [93]. The primary outcome was qualityadjusted life years (QALYs). It was concluded that CSII is a worthwhile investment when targeted at those who might benefit most. Results were most sensitive to the number of hypoglycaemic events per patient. CSII was most cost-effective in patients who had more than two severe hypoglycaemic events per year and who required admission to hospital at least once every year. Cases in which CSII might not be economically viable are cases in which diabetes is well controlled with few severe hypoglycaemic events on conventional insulin therapy.

Pharmacoeconomic studies of insulin lispro used surrogate or short-term clinical endpoints rather than longer-term effects such as vascular complications avoided, and study details were often lacking [89]. Participants in well-designed studies have expressed a preference for lispro-based insulins and have been shown to be willing to pay for the advantages they offer [89]. The limited cost-effectiveness data currently available for insulin lispro suggest that the additional cost associated with the insulin analogue relative to regular human insulin is justified in terms of cost per episode of severe hypoglycaemia avoided or per $1 \%$ reduction in $\mathrm{HbA}_{1 \mathrm{c}}$ level. However, details of methods and sources and determination of costs and robustness of data were often lacking in the available reports [89]. Thus, further research into the pharmacoeconomic implications of short-acting insulin analogue use in the long-term is needed, particularly with respect to effects of indirect costs and those associated with diabetic complications. It would be of much interest to perform such an analysis in a large cohort of type 1 diabetic patients treated in the long term by CSII delivering short-acting insulin analogues.

\section{Conclusions}

Approximately 80 years after the discovery and first human use of insulin, we are still striving to replace insulin in a physiological manner. Administration by CSII is best mimicking basal insulin secretion and meal insulin requirements. The fast-acting nature of insulin analogues provides patients with greater flexibility of their insulin requirements because the bolus can be administered immediately before meals instead of minus 20 to $30 \mathrm{~min}$ before meals as recommended for human regular insulin. This greater flexibility likely leads to improved compliance and a better quality of life for patients using CSII therapy. In addition, better control of postprandial hyperglycaemia leads to slightly improved $\mathrm{HbA}_{1 \mathrm{c}}$ levels, without increasing the risk of hypoglycaemia, as confirmed in a recent metaanalysis of clinical trials comparing CSII with short-acting insulin analogues versus human regular insulin [94]. Most studies tested insulin lispro, although the only clinical trial comparing directly lispro versus aspart insulin reported similar results with the two insulin analogues.

A several-hour interruption of CSII containing insulin lispro is associated with an earlier and greater metabolic deterioration than when the pump delivers human regular insulin. Consequently, patients treated with shortacting insulin analogues (either lispro or aspart) in an insulin pump have to be well educated about the pharmacokinetic properties of their insulin and about the possibility that ketoacidotic deterioration after an interruption of the insulin delivery may occur somewhat 
earlier in comparison to regular human insulin. Finally, the fast-acting insulin analogue, owing to its more rapid absorption from the subcutaneous site, is more effective in correcting this metabolic deterioration after restarting the pump, which may partially compensate for the higher risk of ketoacidosis in case of CSII interruption.

Both CSII and short-acting insulin analogues may offer some improvements regarding quality of life relative to conventional administration of regular human insulin, especially as far as treatment flexibility is concerned. However, further research into the pharmacoeconomic implications of CSII and short-acting insulin analogues in the long term is needed, particularly with respect to effects on indirect costs and those associated with complications of diabetes mellitus.

In conclusion, improved insulins, better methods of insulin delivery, and advances in glucose monitoring will allow to progress towards physiological insulin replacement and, hopefully, reduce the long-term complications of diabetes mellitus.

\section{References}

1. Pickup JC, Keen H, Pavsons JA, Alberti KGMM. Continuous subcutaneous insulin infusion: an approach to achieving normoglycaemia. Br Med $J$ 1978; i: 204-207.

2. Van Cauter E, Polonsky KS, Scheen AJ. Roles of circadian rhythmicity and sleep in human glucose regulation. Endocr Rev 1997; 18: 716-738.

3. Diabetes Control and Complications Trial Research Group. Implementation of treatment protocols in the diabetes control and complications trial. Diabetes Care 1995; 18; 361-376.

4. Haardt MJ, Berne C, Dorange $\mathrm{C}$, et al. Efficacy and indications of CSII revisited: the Hotel Dieu cohort. Diabetic Med 1997; 14: $407-408$.

5. Hanaire-Broutin H, Melki V, Bessieres-Lacombe S, Tauber JP. The Study Group for the Development of Pump Therapy in Diabetes. Comparison of continuous subcutaneous insulin infusion and multiple daily injection regimens using insulin lispro in type 1 diabetic patients on intensified treatment: a randomized study. Diabetes Care 2000; 23: 1232-1235.

6. Pickup J, Martin M, Kerry S. Glycaemic control with continuous subcutaneous insulin infusion compared with intensive insulin injections in patients with type 1 diabetes: meta-analysis of randomised controlled trials. $\mathrm{Br}$ Med $J$ 2002; 324: 705-708.

7. Lenhard MJ, Reeves GD. Continuous subcutaneous insulin infusion. A comprehensive review of insulin pump therapy. Arch Intern Med 2001; 161: 2293-2300.

8. Selam JL. External and implantable insulin pumps: current place in the treatment of diabetes. Exp Clin Endocrinol Diabetes 2001; 109(Suppl. 2): S333-S340.

9. Pickup JC. Is insulin pump treatment justifiable? In Difficult diabetes, Gill GV, Pickup JC, Williams G (eds). Oxford: Blackwell Science, 2001; 205-223.

10. Pickup J, Keen $\mathrm{H}$. Continuous subcutaneous insulin infusion at 25 years: evidence base for the expanding use of insulin pump therapy in type 1 diabetes. Diabetes Care 2002; 25: 593-598.

11. Weissberg-Benchell J, Antisdel-Lomaglio J, Seshadri R. Insulin pump therapy. A meta-analysis. Diabetes Care 2003; 26: 1079 1087.

12. Lee WL, Zinman B. From insulin to insulin analogs: progress.in the treatment of type 1 diabetes. Diabetes Rev 1998; 6: 73-88.

13. Bolli GB, Di Marchi RD, Park GD, Pramming $S$, Koivisto VA. Insulin analogues and their potential in the management of diabetes mellitus. Diabetologia 1999; 42: 1151-1167.

14. Madsbad S. Insulin analogues: have they changed insulin treatment and improved glycaemic control? Diabetes/Metab Res Rev 2002; 18(Suppl. 1): S21-S28.
15. Wilde MI, McTavish D. Insulin lispro. A review of its pharmacological properties and therapeutic use in the management of diabetes melitus. Drugs 1997; 54: 597-614.

16. Anderson $\mathrm{JH}$, Bunelle RL, Koivisto VA, et al. Reduction of postprandial hyperglycemia and frequency of hypoglycemia in IDDM patients on insulin-analog treatment. Diabetes 1997; 46: 265-270.

17. Holleman F, Hoekstra JBL. Insulin lispro. $N$ Engl, $J$ Med 1997; 337: 176-183.

18. Heller S. Insulin lispro: a useful advance in insulin therapy. Expert Opin Pharmacother 2003; 4: 1407-1416.

19. Home PhD, Iindholm A, Hylleberg B, Round $P$ for the U.K. Insulin Aspart Study Group. Improved glycemic control with insulin aspart. A multicenter randomized double-blind crossover trial in type 1 diabetic patients. Diabetes Care 1998; 21: 1904-1909.

20. Raskin P, Guthrie RA, Leiter L, Riis A, Jovanovic L. Use of insulin aspart, a fast-acting insulin analog, as the mealtime insulin in the management of patients with type 1 diabetes. Diabetes Care 2000; 23: 583-588.

21. Home PD, Lindholm A, Riis A for the European Insulin Aspart Study Group. Insulin aspart vs. human insulin in the management of long-term blood glucose control in type 1 diabetes mellitus: a randomised controlled trial. Diabetic Med 2000; 17: 762-770.

22. Lindholm $A$, Jacobsen LV. Clinical pharmacokinetics and pharmacodynamics of insulin aspart. Clin Pharmacokin 2001; 40: 641-659.

23. Chapman TM, Noble S, Goa KL. Insulin aspart: a review of its use in the management of type 1 and type 2 diabetes mellitus. Drugs 2002; 62: 1945-1981.

24. Holleman F, Schmitt $H$, Rottiers $R$, Rees A, Symanowski S, Anderson $\mathrm{JH}$. Reduced frequency of severe hypoglycemia and coma in well-controlled IDDM patients treated with insulin lispro. Diabetes Care 1997; 20: 1827-1832.

25. Heller SR, Amiel SA, Mansell P. Effect of the fast-acting insulin analog lispro on the risk of nocturnal hypoglycemia during intensified insulin therapy. Diabetes Care 1999; 22: 1607-1611.

26. Brunelle RL, Llewelyn J, Anderson JH Jr, Gale EAM, Koivisto VA. Meta-analysis of the effect of insulin lispro on severe hypoglycemia in patients with type 1 diabetes. Diabetes Care 1998; 21: 1726-1731.

27. Lalli $C$, Ciofetta $M$, Del Sindaco $P$, et al. Long-term intensive treatment of type 1 diabetes with the short-acting insulin analog lispro in variable combination with NPH insulin at mealtime. Diabetes Care 1999; 22: 468-477.

28. Rönnemaa $T$, Viikari J. Reducing snacks when switching from conventional soluble to lispro insulin treatment: effects on glycaemic control and hypoglycaemia. Diabetic Med 1998; 15: 601-607.

29. Ebeling P, Jansson P-A, Smith U, Lalli C, Bolli GB, Koivisto VA. Strategies toward improved control during insulin lispro therapy in IDDM. Diabetes Care 1997; 20: 1287-1289.

30. Kraegen EW, Chisholm DJ. Pharmacokinetics of insulin. Implications for continuous subcutaneous insulin infusion therapy. Clin Pharmacokin 1985; 10: 303-314.

31. Scheen AJ. Pharmacocinétique de l'insuline administrée par voie sous-cutanée. Application au traitement par pompe portable. Diabete Metab 1989; 15: 128-138.

32. Lougheed WD, Zinman B, Strack TR, et al. Stability of insulin lispro in insulin infusion systems. Diabetes Care 1997; 20: 1061-1065.

33. Zinman $B$. Insulin pump therapy and rapid acting insulin: what have we learned? Int $J$ Clin Pract 2001; 123(Suppl.): 47-50.

34. Bode $B$, Weinstein $\mathrm{R}$, Bell $\mathrm{D}$, et al. Comparison of insulin aspart with buffered regular insulin and insulin lispro in continuous subcutaneous insulin infusion. Diabetes Care 2002; 25: $439-444$

35. Mecklenburg RS, Benson EA, Benson JW, et al. Acute complications associated with insulin infusion pump therapy: report of experience with 161 patients. JAMA 1984; 252: 3265-3269.

36. Bending JJ, pickup JC, Keen H. Frequency of diabetic ketoacidosis and hypoglycaemic coma during treatment with continuous subcutaneous insulin infusion. Audit of medical care. Am J Med 1985; 79: 685-691.

37. Castillo MJ, Scheen A, Lefébvre PJ. Treatment with insulin infusion pumps and ketoacidotic episodes: from physiology to troubleshooting. Diabetes/Metab Rev 1995; 11: 161-177. 
38. Zinman B, Tildesley $H$, Chiasson J-L, Tsui E, Strack T. Insulin lispro in CSII. Results of a double-blind crossover study. Diabetes 1997; 46: 440-443.

39. Schmauss $S$, König A, Landgraf R. Human insulin analogue [Lys(B28),PRO(B29)]: the ideal pump insulin? Diabetic Med 1998; 15: 247-249.

40. Melki V, Renard E, Lassmann-Vague V, et al. Improvement of $\mathrm{HbA}_{1 \mathrm{c}}$ and blood glucose stability in IDDM patients treated with lispro insulin analog in external pumps. Diabetes Care 1998; 21: 977-982.

41. Renner R, Pfützner A, Trautmann M, et al. Use of insulin lispro in continuous subcutaneous insulin infusion treatment. Results of a multicenter trial. Diabetes Care 1999; 22: 784-788.

42. Johansson UB, Adamson UCK, Lins PES, Wredling RAM. The Swedish Multicenter Lispro Insulin Study. Improved blood glucose variability, $\mathrm{HbA}_{1 c}$ Insuman Infusat and less insulin requirement in DDM patients using insulin lispro in CSII. Diabetes Metab 2000; 26: 192-196.

43. Raskin $\mathrm{P}, \mathrm{Holcombe} \mathrm{JH}$, Tamborlane WV, et al. A comparison of insulin lispro and buffered regular human insulin administered via continuous subcutaneous insulin infusion pump. $J$ Diabetes Complications 2001; 15: 295-300.

44. Campbell RK, Sclar DA, Robison LM, et al. Impact on clinical status and quality of life of switching from regular human insulin to insulin lispro among patients using insulin pumps. Diabetes Educator 1998; 24: 95-99.

45. Garg SK, Anderson JH, Gerard LA, et al. Impact of insulin lispro on $\mathrm{HbA}_{1 \mathrm{c}}$ values in insulin pump users. Diab Obesity Metab 2000; 2: $307-311$.

46. Catargi B, Breihl D, Roger P, Tabarin A. Glucose profiles in a type 1 diabetic patient successively treated with CSII using regular insulin, lispro and an implantable insulin pump. Diabetes Metab 2000; 26: 210-214

47. Catargi B, Meyer L, Melki V, Renard E, Jeandidier $N$ for the EVADIAC Study Group. Comparison of blood glucose stability and $\mathrm{HbA}_{1 \mathrm{c}}$ between implantable insulin pumps using U40O HOE $21 \mathrm{PH}$ insulin and external pumps using lispro in type 1 diabetic patients: a pilot study. Diabetes Metab 2002; 28: 133-137.

48. Tsui EY, Chiasson JL, Tildesley H, Barnie A Simkins S, Strack T. Counterregulatory hormone responses after long-term continuous subcutaneous insulin infusion with lispro insulin. Diabetes Care 1998; 21: 93-96.

49. Homko C, Deluzio A, Jimenez C, Kolaczynski JW, Boden G. Comparison of insulin aspart and lispro. Pharmacokinetic and metabolic effects. Diabetes Care 2003; 26: 2027-2031.

50. Bode BW, Strange P. Efficacy, safety, and pump compatibility of insulin aspart used in continuous subcutaneous insulin infusion therapy in patients with type 1 diabetes. Diabetes Care 2001; 24: 69-72.

51. Guerci B, Jeandidier N, Lassmann-Vague V, Renard E, HanaireBroutin $\mathrm{H}$. Comment utiliser l'analogue de l'insuline Lys-Pro en perfusion sous-cutanée continue par pompe portable? Diabetes Metab 2000; 26: 513-519.

52. Krzentowski G, Scheen A, Castillo M, Luyckx AS, Lefebvre PJ. A 6-hour nocturnal interruption of a continuous subcutaneous insulin infusion: 1. Metabolic and hormonal consequences and scheme for a prompt return to adequate control. Diabetologia 1983; 24: 314-318.

53. Scheen A, Henrivaux $P$, Jandrain $B$, Paolisso G, Lefêbvre $P$. Prevention of metabolic alterations by insulin supplements administered either before or after 2-h nocturnal interruption of CSII. Diabetes Care 1987; 10: 567-572.

54. Scheen AJ, Castillo MJ, Lefèbvre PJ. Interruption inopinée ou délibérée d'une perfusion continue sous-cutanée d'insuline: conseils pratiques. Diabete Metab 1993; 19: 597-600.

55. Attia N, Jones TW, Holcombe J, Tamborlane WV. Comparison of human regular and lispro insulins after interruption of continuous subcutaneous insulin infusion and in the treatment of acutely decompensated IDDM. Diabetes Care 1998; 21: 817-821.

56. Reichel A, Rietzsch H, Kohler H.J, et al. Cessation of insulin infusion at night-time during CSII-therapy: comparison of regular human insulin and insulin lispro. Exp Clin Endocrinol Diabetes 1998; 106: 168-172.

57. Guerci B, Meyer L, Sallé A, et al. Comparison of metabolic deterioration between insulin analog and regular insulin after a 5-hour interruption of a continuous subcutaneous insulin infusion in type 1 diabetic patients. I Clin Endocrinol Metab 1999; 84: 2673-2678.
58. Dahl JS, Toriesen P, Hanssen $K$, Sandvik L, Aagenes O. Increase in insulin antibodies during continuous subcutaneous insulin infusion and multiple-injection therapy in contrast to conventional treatment. Diabetes 1987; 36: 1-5.

59. Olsen CL, Chan E, Turner DS, et al. Insulin antibody responses after long-term intraperitoneal insulin administration via implantable programmable insulin delivery systems. Diabetes Care 1994; 17: 169-176.

60. Walford S, Allison SP, Reeves WG. The effect of insulin antibodies on insulin dose and diabetic control. Diabetologia 1982; 22: 106-110.

61. Roach P, Varshavsky JA, Gantner $\mathrm{K}$, Anderson JH. Insulin antibody-formation during treatment with human insulin or insulin lispro does not affect insulin dose requirements (Abstract). Diabetes 1996; 45(Suppl. 2): 958.

62. Scheen A, Henrivaux P, Jandrain B, Lefebvre P. Anti-insulin antibodies and metabolic deterioration after interruption of continuous subcutaneous insulin infusion. Diabetes Care 1986; 9: $673-674$

63. Montana E, Fernandez-Castaner M, Rosel P, Gomez JM, Vinzia C, Soler J. The influence of insulin antibodies on metabolic deterioration after interruption of continuous subcutaneous insulin infusion. Diab Metab 1990; 16: 220-225.

64. Fineberg NS, Fineberg SG, Anderson $J H$, Birkett MA, Gib son RG, Hufferd S. Immunologic effects of insulin lispro [(Lys (B28), Pro (B29) human insulin)] in IDDM and NIDDM patients previously treated with insulin. Diabetes 1996; 45: 1750-1754

65. Fineberg SE, Huang J, Brunelle R, Gulliya KS, Anderson JH Jr. Effect of long-term exposure to insulin lispro on the induction of antibody response in patients with type 1 or type 2 diabetes. Diabetes Care 2003; 26: 89-96.

66. Lahtela JT, Knip M, Paul R, Antonen J, Salmi J. Severe antibodymediated human insulin resistance: successful treatment with the insulin analog lispro: a case report. Diabetes Care 1997; 20: $71-73$.

67. Kumar D. Lispro analog for treatment of generalized allergy to human insulin. Diabetes Care 1997; 20: 1357-1359.

68. Eapen SS, Connor EL, Gern JE. Insulin desensitisation with insulin lispro and an insulin pump in a 5-year-old child. Ann Allergy Asthma Immunol 2000; 85: 395-397.

69. Näf S, Esmatjes E, Recasens M, et al. Continuous subcutaneous insulin infusion to resolve an allergy to human insulin. Diabetes Care 2002; 25: 634-635.

70. Sola-Gazagnes A, Pecquet C, Radermecker R, et al. Successful treatment of insulin allergy in a type 1 diabetic patient by means of constant subcutaneous pump infusion of insulin (Letter). Diabetes Care 2003; 26: 2961-2962.

71. Griffin ME, Feder A, Tamborlane WV. Lipoatrophy associated with lispro in insulin pump therapy (Letter). Diabetes Care 2001; $24: 174$.

72. Ampudia-Blasco FJ, Hasbum B, Carmena R. A new case of lipoatrophy with lispro insulin in insulin pump therapy. Diabetes Care 2003; 26: 953-954.

73. Gabbe SG. New concepts and applications in the use of the insulin pump during pregnancy. $J$ Matern Fetal Med 2000; 9: 42-45.

74. Gabbe SG, Holing E, Temple P, Brown ZA. Benefits, risks, costs, and patient satisfaction associated with insulin pump therapy for the pregnancy complicated by type 1 diabetes mellitus. Am $J$ Obstet Gynecol 2000; 182: 1283-1291.

75. El-Sayed YY, Lyell DJ. New therapies for the pregnant patient with diabetes. Diabetes Technol Ther 2001; 3: 635-640.

76. Jovanovic L, Ilic S, Pettit DJ, et al. Metabolic and immunologic effects of insulin lispro in gestational diabetes. Diabetes Care 1999; 22: 1422-1427.

77. Bhattacharyya A, Brown S, Hughes S, Vice PA. Insulin lispro and regular insulin in pregnancy. $Q J$ Med 2001; 94: 255-260.

78. Calle-Pascual AL, Bagazgoitia J, Calle JR, Charro A, Maranes JP. Use of insulin lispro in pregnancy. Diabetes Nutr Metab 2000; 13: $173-177$.

79. Buchbinder A, Miodovnik M, Khoury J, Sibai BM. Is the use of insulin lispro safe in pregnancy? $J$ Matern Fetal Neonatal Med 2002; 11: 232-237.

80. Masson EA, Patmore JE, Brash PD, et al. Pregnancy outcome in Type 1 diabetes mellitus treated with insulin lispro (Humalog). Diabetic Med 2003; 20: 46-50.

81. Boskovic R, Feig DS, Derewlany L, Knie B, Portnoi G, Koren G. Transfer of insulin lispro across the human placenta: in vitro perfusion studies. Diabetes Care 2003; 26: 1390-1394. 
82. Pettitt DJ, Ospina P, Kolaczynski JW, Jovanovic L. Comparison of an insulin analog, insulin aspart, and regular human insulin with no insulin in gestational diabetes mellitus. Diabetes Care 2003; 26: 183-186.

83. American Diabetes Association. Continuous subcutaneous insulin infusion. Diabetes Care 2003; 26(Suppl. 1): S125.

84. Kitzmiller JL, Main E, Ward B, Theiss T, Peterson DL. Insulin lispro and the development of proliferative diabetic retinopathy during pregnancy. Diabetes Care 1999; 22: 874-875.

85. Buchbinder A, Miodovnik M, McElvy S, et al. Is insulin lispro associated with the development or progression of diabetic retinopathy during pregnancy? Am J Obstet Gynecol 2000; 183: $1162-1165$.

86. Loukovaara S, Immonen I, Teramo KA, Kaaja R. Progression of retinopathy during pregnancy in type 1 diabetic women treated with insulin lispro. Diabetes Care 2003; 23: 1193-1198.

87. Bruttomesso D, Pianta A, Crazzolara D, et al. Continuous subcutaneous insulin infusion (CSII) in the Veneto region: efficacy, acceptability and quality of life. Diabet Med 2002; 19: 628-634.

88. Wolf FM, Jacober SJ, Wolf L, Cornell RG, Floyd JC. Quality of life activities associated with adherence to insulin infusion pump therapy in the treatment of insulin dependent diabetes mellitus. $J$ Clin Epidemiol 1989; 42: 1129-1136.

89. Dunn CJ, Plosker GL. Insulin lispro: a pharmacoeconomic review of its use in diabetes mellitus. PharmacoEconomics 2002; 20: 989-1025.

90. Kotsanos JG, Vignati L, Huster W, et al. Health-related qualityof-life results from multinational clinical trials of insulin lispro: assessing benefits of a new diabetes therapy. Diabetes Care 1997; 20: 948-958.

91. Bott U, Ebrahim S, Hirschberger S, Skovlund SE. Effect of the rapid-acting insulin analogue insulin aspart on quality of life and treatment satisfaction in patients with type 1 diabetes. Diabet Med 2003; 20: 626-634.

92. De Witt DE, Hirsch IB. Outpatient insulin therapy in type 1 and type 2 diabetes mellitus. JAMA 2003; 289: 2254-2264.

93. Scuffham P, Carr L. The cost-effectiveness of continuous subcutaneous insulin infusion compared with multiple daily injections for the management of diabetes. Diabet Med 2003; 20: 586-593.

94. Colquitt J, Royle P, Waugh N. Are analogue insulins better than soluble in continuous subcutaneous insulin infusion? Results of a meta-analysis. Diabet Med 2003; 20: 863-866. 